\title{
AN ENERGY-BASED APPROACH FOR DETECTION AND CHARACTERIZATION OF SUBTLE ENTITIES WITHIN LASER SCANNING POINT-CLOUDS
}

\author{
Reuma Arav* and Sagi Filin \\ Mapping and GeoInformation Engineering \\ Technion - Israel Institute of Technology \\ Haifa, 32000 \\ reumaa,filin@technion.ac.il
}

Commission III, WG III/2

KEY WORDS: Energy-based methods, Level-set, Terrestrial Laser Scanning, Sinkholes, Geomorphology, Feature Extraction

\begin{abstract}
:
Airborne laser scans present an optimal tool to describe geomorphological features in natural environments. However, a challenge arises in the detection of such phenomena, as they are embedded in the topography, tend to blend into their surroundings and leave only a subtle signature within the data. Most object-recognition studies address mainly urban environments and follow a general pipeline where the data are partitioned into segments with uniform properties. These approaches are restricted to man-made domain and are capable to handle limited features that answer a well-defined geometric form. As natural environments present a more complex set of features, the common interpretation of the data is still manual at large. In this paper, we propose a data-aware detection scheme, unbound to specific domains or shapes. We define the recognition question as an energy optimization problem, solved by variational means. Our approach, based on the level-set method, characterizes geometrically local surfaces within the data, and uses these characteristics as potential field for minimization. The main advantage here is that it allows topological changes of the evolving curves, such as merging and breaking. We demonstrate the proposed methodology on the detection of collapse sinkholes.
\end{abstract}

\section{INTRODUCTION}

Airborne laser scanning technology offers detailed description of landforms and surface variability. It provides an excellent means for measuring and monitoring morphological changes across a variety of spatial scales. These capabilities are leading to greater use of laser technology for detection and characterization of surface features, natural geohazards, and landforms. As an example, Booth et al. (2009); Eeckhaut et al. (2012) automatically map landslides using surface roughness estimations, Razak et al. $(2011,2013)$ map terrain in complex forested areas following filterization, and Bollmann et al. (2015) assess glacier activity by estimating its thickness change. Laser scanning has also been utilized for characterizing surficial geohazards, including landslides (e.g., Eeckhaut et al., 2012; Fey et al., 2015), debris flow (e.g., Staley et al., 2006), or volcanic features (e.g., Jones et al., 2015).

Increasing number of applications, span of studied phenomena, and amount of data collected, all call for efficient detection and analysis means of natural hazards. While autonomous models for surface-feature-extraction have been reported, the majority identify a unique topographic signature that faithfully reflects a particular geomorphic process (Roering et al., 2013). Berti et al. (2013) categorize high-resolution DEMs to an 'active' and 'inactive' slope, based on roughness estimations, and compare it to a ground truth value. The predictive maps were accep 'table for active slopes $(90 \%)$ but their accuracy decreased dramatically in highly vegetated areas. Jara-Muñoz et al. (2015b) use surfaceclassification-model (Bowles and Cowgill, 2012) which linearly combines terrain roughness and slope as a base-map for identifying different terrace levels their extent and elevation distribution. In order to find the shoreline angles (notches), maximum elevation is extracted from predefined swath profiles (Jara-Muñoz et al., 2015a). Points representing the undisturbed abrasion platform and paleo-cliff are picked and fitted by linear regression. Civico et al. (2015) carry morphotectonic analysis via airborne laser scan-based DEMs. Topographic profiles between the basin floor and the highest footwall surfaces are constructed, according to a best-displaced geomorphic marker (an identifiable feature that has been displaced). In both analyses specific swaths are chosen for further analysis of the surface geomorphology. Lin et al. (2013) qualitatively identify subtle features by visualizing datasets according to an openness-angles concept, which defines each point as the average of eight zenith or nadir angles of a surface spot along compass directions within radial limit (Yokoyama et al., 2002). While attempting to quantify phenomena from scans, most approaches are rudimentary and ad-hoc to some degree.

We present in this paper an autonomous detection model, and demonstrate it on collapse sinkholes using airborne laser scanning data. Geometrically, sinkholes are oval-shaped features, ranging in size from sub-meter dimensions to several tens of meters as they develop. Over time, they develop into large fields reaching up to 100 per site (Fig. ??). Because of their sudden appearance and hazardous nature, it is important to distinguish them and localize their position at an early stage. Until recently, sinkhole monitoring was carried out using aerial photography and earlier on, by land surveying. However, it is clear that their number makes them difficult to monitor terrestrially, and they are difficult to be tracked using aerial photography as objects with similar radiometric signatures, e.g., shadows or shrubs, complicate distinguishing between actual surface depressions and artificial ones. Filin and Baruch (2010) and Baruch and Filin (2011) suggested an energy-based detection, where dominant concave areas were first detected via curvature maps, according to which the curve was to propagate. However, it required a good initialization of the sinkhole boundary. Considering the detection as a segmentation problem rather than 'edge-based', we propose a level-set method and present a constraint-free model whose initialization is arbitrary and no prior knowledge is needed. As this paper demonstrates, the proposed model features good detection 
and can characterize multiple objects within a scene within a single application. Therefore, and while focusing on sinkholes, this paper demonstrates the ability to detect minute morphologic features on a large-scale.
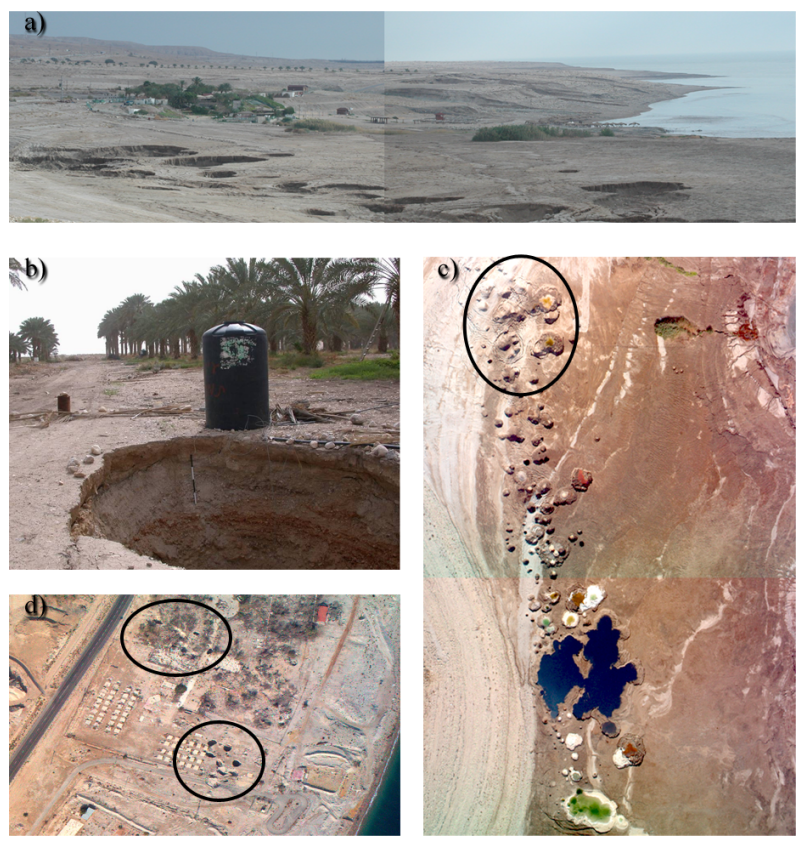

Figure 1. Collapse sinkholes along the Dead Sea coast

\section{DETECTION}

Collapse sinkholes are characterized by a drop in the topography. They have closed smooth polygonal boundaries that follow the transition between the depression and surrounding terrain. This transition is identified, in most cases, by a change in the gradient value. Filin and Baruch (2010); Baruch and Filin (2011) cast the boundary detection as an energy-minimization problem. This formulation leads to sinkhole border modeling as an active contour with a shape guided by internal, spline, and external, boundary, forces (Kass et al., 1988). Solving the snakes problem accounts to minimization of the energy that associates the parametrized planar curve $\mathcal{C}(q)$ : $[0,1]$ within a point-cloud, i.e.:

$$
\min E(\mathcal{C})=\int_{0}^{1}\left(E_{\text {int }}(\mathcal{C}(q))+E_{\text {ext }}(\mathcal{C}(q))\right) d q
$$

where $E_{\text {int }}$, the internal spline energy due to bending, and $E_{\text {ext }}$, the external energy originating from the terrain (by means of the laser data). However, as this functional relies on the parametrization $q$, it does not depend solely on the curve geometry, and thus may present a problem for an edge-detection scheme. Moreover, when considering more than a solitary sinkhole, it is impossible to detect all simultaneously with only one curve was initialized.

Instead, we pursue the geodesic active contours (Caselles et al., 1997) based on the level-set approach (Osher and Sethian, 1988), in which the boundary $\mathcal{C}$ is represented by the zero level curve. It can be shown (Caselles et al., 1997) that Eq. (1) satisfies the Hamilton-Jacobi equation, and can be formulated accordingly by:

$$
E(\mathcal{C}(q))=\int_{0}^{1} g\left(|\nabla I(\mathcal{C}(q) \mid)| \mathcal{C}^{\prime}(q) \mid d q\right.
$$

where $I$ is the point-cloud, and $g(\cdot)$ is a velocity field, monotonically decreasing function, normally an edge detection function. This means that we seek the geodesic curve based on the surrounding properties. The minimization is carried via gradient descent and thus, the level-sets move according to:

$$
\frac{\partial \mathcal{C}(q, t)}{\partial t}=g(I)(c+\kappa) \overrightarrow{\mathcal{N}}-(\nabla g(|\nabla I|) \cdot \overrightarrow{\mathcal{N}}) \overrightarrow{\mathcal{N}}
$$

with $\overrightarrow{\mathcal{N}}$ is the unit inward normal to the curve, and $\kappa$ the Euclidean curvature, and $c$ a constant. Assuming that the curve $\mathcal{C}$ is a level-set function of $\phi(x, y)$, and $\kappa=\operatorname{div}\left(\frac{\nabla \phi}{|\nabla \phi|}\right)$, the boundary evolution can be formulated as:

$$
\frac{\partial \phi(x, y, t)}{\partial t}=g(I)|\nabla \phi| \operatorname{div}\left(\frac{\nabla \phi}{|\nabla \phi|}\right)+c g(I)|\nabla \phi|
$$

Eq. (4) shows that the velocity field dictates the curve evolution, and therefore convergence largely relies on its definition. The transition between sinkholes and the terrain is expressed by height differences, and therefore the velocity field is initially defined as the gradient map, $g=\nabla f$.

Although strong gradients in $\nabla f$ point towards the sinkhole boundary near the edge, their dominance decreases farther from the sinkholes immediate vicinity, and the contour evolution becomes sensitive to local perturbations and background noise. This phenomenon is particularly relevant in homogeneous regions, where heights are nearly constant and $\nabla f$ fluctuates around zero. To expedite convergence, an alternative force field (Xu and Prince, 1998; Paragios et al., 2001) replaces the gradient map, which consists of a two-dimensional vector field $[\mathbf{v}(p)=(u(p), v(p), p=$ $(x, y)]$. This gradient vector flow minimizes the energy such that areas where the information is constant (i.e., $|\nabla f| \rightarrow 0$ ) will be dominated by the partial derivatives of the vector field; large variations of the surface gradients induce the sole use of $\nabla f$. That is to say:

$$
E(\mathbf{v})=\iint \mu\left(u_{x}^{2}+u_{y}^{2}+v_{x}^{2}+v_{y}^{2}\right)+|\nabla f|^{2}|\mathbf{v}-\nabla f|^{2} d x d y
$$

with $\mu$ a blending parameter. The minimization is achieved by solving the the Euler-Lagrange equation, and so by the diffusion equation

$$
\begin{aligned}
& \mu \nabla^{2} u-\left(u-f_{x}\right)\left(f_{x}^{2}+f_{y}^{2}\right)=0 \\
& \mu \nabla^{2} v-\left(v-f_{y}\right)\left(f_{x}^{2}+f_{y}^{2}\right)=0
\end{aligned}
$$

Eq. (6), can be iteratively solved by differential corrections to the vector field:

$$
\begin{aligned}
& u_{i+1}=u_{i}+\mu \nabla^{2} u_{i}-\left(u_{i}-f_{x}\right)\left(f_{x}^{2}+f_{y}^{2}\right) \\
& v_{i+1}=v_{i}+\mu \nabla^{2} v_{i}-\left(v_{i}-f_{y}\right)\left(f_{x}^{2}+f_{y}^{2}\right)
\end{aligned}
$$

Iterating until no significant update is reached provides the gradient vector flow field.

The active contour then evolves according to the updated gradient vector:

$$
\frac{\partial \mathcal{C}(q, t)}{\partial t}=(\hat{\mathbf{v}} \cdot \overrightarrow{\mathcal{N}}) \overrightarrow{\mathcal{N}}
$$


where $\hat{\mathbf{v}}=\mathbf{v} /|\mathbf{v}|-$ the normalized gradient vector field. The proposed field aims maintaining large gradient magnitudes near the edges, but also extending the influence of strong gradients farther into homogeneous regions by minimizing the energy functional.

\section{ANALYSIS AND DISCUSSION}

The application of the proposed detection methodology is demonstrated on high-resolution airborne laser scanning data along the Dead-Sea coast whose ongoing desiccation has triggered a range of dramatic geomorphic processes, among them are the incision of gullies and rapid development collapse sinkholes. The latter are localized land-features, which appear in various sizes and forms and whom formation is generally attributed to evolution of subterranean cavities, ultimately leading to collapse of the upper soil layer. Cavities are usually formed due to shrinkage of inner soft sediment layers which in turn are leading to dissolution within layers of soluble (usually carbonate) rocks due to water diversion or water percolation (Neal, 1998; Tharp, 1999; Neal and Johnson, 2002; Salvati and Sasowsky, 2002; Abelson et al., 2006). They endanger infrastructures and regional development (Kaufmann and Quinif, 2002; Abelson et al., 2006), and led to loss of human lives.

Along the Dead Sea coastal plains, sinkholes have been developing for more than two decades (Fig. ??) and since the early $2000 \mathrm{~s}$ their development began accelerating (Abelson et al., 2009). Their formation is generally ascribed to a rapid drop in the Dead Sea lake level, leading in turn to dissolution of a thick layer of salt (located in a depth of 20 to $50 \mathrm{~m}$ below surface) by fresh water running in the subsurface toward the receding lake (Yechieli et al., 2006; Abelson et al., 2006, 2009; Filin et al., 2014). Halite dissolution is much more rapid compared to carbonates/lime, leading to faster processes than those reported in the literature (Abelson et al., 2006). Sinkholes have been observed along an approximate $70 \mathrm{~km}$ strip of land; hundreds of them are found nowadays along large parts of the coast. Their formation is generating a severe threat to the future of the region, leading to abandonment of fertile agricultural fields and popular sea resorts in some areas, and the halting of regional development.

Laser scanning data were acquired with a point density of approx. 4 points $/ \mathrm{m}^{2}$ and in overlapping regions between swaths reached approx. 6 point $/ \mathrm{m}^{2}$. Accuracy was evaluated by ground reference points, showing elevation accuracy of $\pm 7 \mathrm{~cm}$. For computational convenience, data was converted into a $0.5 \mathrm{~m}$ grid (conforming to the data density). The selected set of sinkholes and their detection process is illustrated in (Fig. 2 and ??), which includes two bowllike shaped sinkholes, whose geometry is somewhat different and more challenging than the typical cylindrical ones, and is typical to mudflats areas. Their depth is approx. 3-5 m. Fig. (2(b)) depicts the velocity field, here computed by the gradient vector flow and the dataset gradients. Note that the inner collapses signal within the lower sinkhole is more significant than the upper one, due to smaller height differences within the sinkhole.

Fig. (??) presents the level-set evolution. An arbitrary signed distance function, so that the level-set will encompass the entire scene, is the initial stage (Fig. (??), right). The relatively smooth bowl-like shape and relatively homogeneous surface dictate an almost constant convergence of the level-set contour before reaching the boundary, where the contour split into two separated objects. An abrupt change in depth within the lower sinkhole formed yet another segment in the final stages. This indicate another collapse phase, but in order to avoid a sinkholewithin-sinkhole morphology, it can also be excluded via topological analysis of the contours.

\section{CONCLUSIONS}

This paper demonstrated an autonomous model for extracting and characterizing collapse sinkholes. As the analysis has demonstrated, the model performs well and is able to detect sub-collapses within the sinkholes themselves. The proposed model has the advantage of detecting multiple objects within one scene, without prior knowledge as to the number of the sinkholes and their whereabouts, making it applicable over large areas. Clearly, the ability to detect autonomously natural features suggests great prospects in utilizing laser scanning data for identifying and characterizing a variety of geomorphic entities.

\section{REFERENCES}

Abelson, M., Gabay, R., Shalev, E. and Yechieli, Y., 2009. Sinkholes hazard around the evaporation ponds - dead sea southern basin. Technical Report GSI/27/2009, Geolgical Survey of Israel, Jerusalem.

Abelson, M., Yechieli, Y., Crouvi, O., Baer, G., Wachs, D., Bein, A. and Shtivelman, V., 2006. Evolution of the dead sea sinkholes. Special Papers-Geological Society of America 401, pp. 241.

Baruch, A. and Filin, S., 2011. Detection of gullies in roughly textured terrain using airborne laser scanning data. ISPRS Journal of Photogrammetry and Remote Sensing 66(5), pp. 564-578.

Berti, M., Corsini, A. and Daehne, A., 2013. Comparative analysis of surface roughness algorithms for the identification of active landslides. Geomorphology 182, pp. $1-18$.

Bollmann, E., Girstmair, A., Mitterer, S., Krainer, K., Sailer, R. and Stöter, J., 2015. A rock glacier activity index based on rock glacier thickness changes and displacement rates derived from airborne laser scanning. Permafrost and Periglacial Processes 26(4), pp. 347-359.

Booth, A. M., Roering, J. J. and Perron, J. T., 2009. Automated landslide mapping using spectral analysis and high-resolution topographic data: Puget sound lowlands, washington, and portland hills, oregon. Geomorphology 109(34), pp. $132-147$.

Bowles, C. J. and Cowgill, E., 2012. Discovering marine terraces using airborne lidar along the mendocino-sonoma coast, northern california. Geosphere 8(2), pp. 386-402.

Caselles, V., Kimmel, R. and Sapiro, G., 1997. Geodesic active contours. International journal of computer vision 22(1), pp. 6179.

Civico, R., Pucci, S., Martini, P. M. D. and Pantosti, D., 2015. Morphotectonic analysis of the long-term surface expression of the 2009 l'aquila earthquake fault (central italy) using airborne lidar data. Tectonophysics 644645, pp. 108 - 121.

Eeckhaut, M. V. D., Kerle, N., Poesen, J. and Hervás, J., 2012. Object-oriented identification of forested landslides with derivatives of single pulse lidar data. Geomorphology 173-174, pp. 30 $-42$

Fey, C., Rutzinger, M., Wichmann, V., Prager, C., Bremer, M. and Zangerl, C., 2015. Deriving 3d displacement vectors from multi-temporal airborne laser scanning data for landslide activity analyses. GIScience \& Remote Sensing 52(4), pp. 437-461.

Filin, S. and Baruch, A., 2010. Detection of sinkhole hazards using airborne laser scanning data. Photogrammetric Engineering \& Remote Sensing 76(5), pp. 577-587. 


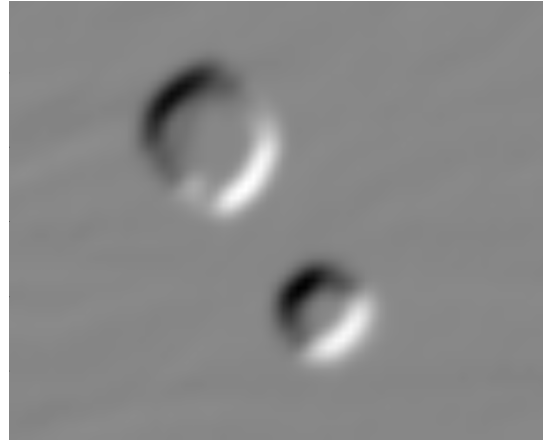

(a)

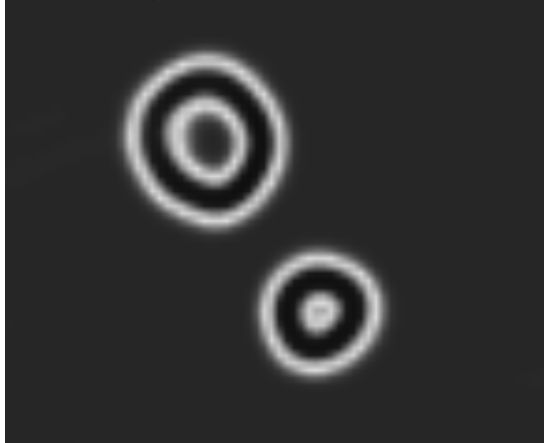

(b)

Figure 2. a) Shaded relief of two sinkholes; b) Edge map used for the level-set evolution. Note there are multiple collapses within the sinkhole.
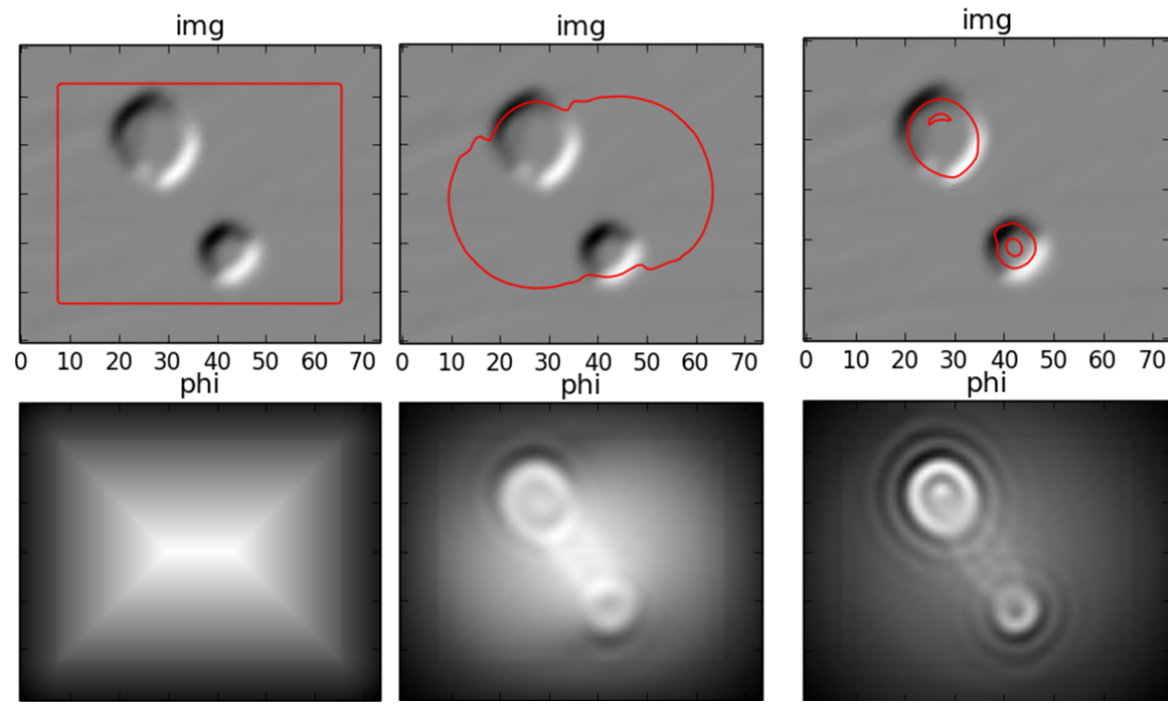

Figure 3. Level-set evolution for the detection of sinkholes. Right to left: initialization, evolution, and final results; Top: the level-set contour; Bottom: the level-set function

Filin, S., Avni, Y., Baruch, A., Morik, S., Arav, R. and Marco, S., 2014. Characterization of land degradation along the receding dead sea coastal zone using airborne laser scanning. Geomorphology 206, pp. $403-420$.

Jara-Muñoz, J., Melnick, D. and Strecker, M. R., 2015a. Ter-

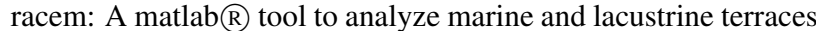
using high-resolution topography. Geosphere pp. GES01208-1.

Jara-Muñoz, J., Melnick, D., Brill, D. and Strecker, M. R., 2015b. Segmentation of the 2010 maule chile earthquake rupture from a joint analysis of uplifted marine terraces and seismic-cycle deformation patterns. Quaternary Science Reviews 113, pp. $171-$ 192. Megathrust Earthquakes and Sea-level Change: a Tribute to George Plafker.

Jones, L. K., Kyle, P. R., Oppenheimer, C., Frechette, J. D. and Okal, M. H., 2015. Terrestrial laser scanning observations of geomorphic changes and varying lava lake levels at erebus volcano, antarctica. Journal of Volcanology and Geothermal Research 295, pp. $43-54$.

Kass, M., Witkin, A. and Terzopoulos, D., 1988. Snakes: Active contour models. International journal of computer vision 1(4), pp. 321-331.
Kaufmann, O. and Quinif, Y., 2002. Geohazard map of covercollapse sinkholes in the 'tournaisis' area, southern belgium. Engineering Geology 65, pp. 117-124.

Lin, Z., Kaneda, H., Mukoyama, S., Asada, N. and Chiba, T., 2013. Detection of subtle tectonic - geomorphic features in densely forested mountains by very high-resolution airborne lidar survey. Geomorphology 182, pp. $104-115$.

Neal, J., 1998. Sinkholes in evaporite rocks. Am Sci 86, pp. 3851McCalpin.

Neal, J. T. and Johnson, K. S., 2002. Mccauley sinks: A compound breccia pipe in evaporite karst, holbrook basin, arizona, usa. Carbonates and evaporites 17(2), pp. 98-106.

Osher, S. and Sethian, J. A., 1988. Fronts propagating with curvature-dependent speed: Algorithms based on hamiltonjacobi formulations. Journal of Computational Physics 79(1), pp. $12-49$.

Paragios, N., Mellina-Gottardo, O. and Ramesh, V., 2001. Gradient vector flow fast geodesic active contours. In: Computer Vision, 2001. ICCV 2001. Proceedings. Eighth IEEE International Conference on, Vol. 1, IEEE, pp. 67-73.

Razak, K. A., Santangelo, M., Westen, C. J. V., Straatsma, M. W. and de Jong, S. M., 2013. Generating an optimal $\{$ DTM $\}$ from 
airborne laser scanning data for landslide mapping in a tropical forest environment. Geomorphology 190, pp. 112-125.

Razak, K., Straatsma, M., van Westen, C., Malet, J.-P. and de Jong, S., 2011. Airborne laser scanning of forested landslides characterization: Terrain model quality and visualization. Geomorphology 126(1-2), pp. 186-200.

Roering, J. J., Mackey, B. H., Marshall, J. A., Sweeney, K. E., Deligne, N. I., Booth, A. M., Handwerger, A. L. and CerovskiDarriau, C., 2013. 'you are here': Connecting the dots with airborne lidar for geomorphic fieldwork. Geomorphology 200, pp. $172-183$. The Field Tradition in Geomorphology 43rd Annual Binghamton Geomorphology Symposium, held 21-23 September 2012 in Jackson, Wyoming $\{$ USA $\}$.

Salvati, R. and Sasowsky, I. D., 2002. Development of collapse sinkholes in areas of groundwater discharge. Journal of Hydrology 264(1), pp. 1-11.

Tharp, T. M., 1999. Mechanics of upward propagation of covercollapse sinkholes. Engineering geology 52(1), pp. 23-33.

$\mathrm{Xu}, \mathrm{C}$. and Prince, J., 1998. Snakes, shapes, and gradient vector flow. Image Processing, IEEE Transactions on 7(3), pp. 359-369.

Yechieli, Y., Abelson, M., Bein, A., Crouvi, O. and Shtivelman, V., 2006. Sinkhole swarms along the dead sea coast: reflection of disturbance of lake and adjacent groundwater systems. Geological Society of America Bulletin 118(9-10), pp. 1075-1087.

Yokoyama, R., Shirasawa, M. and Pike, R. J., 2002. Visualizing topography by openness: a new application of image processing to digital elevation models. Photogrammetric engineering and remote sensing 68(3), pp. 257-266. 